\title{
Evaluation of Cariogenic Bacteria
}

Fusao Nishikawaraa,b,c, DDS, PhD

Yoshiaki Nomura ${ }^{\mathrm{a}, \mathrm{b}}$, DDS, PhD

Susumu Imaib, PhD

Akira Sendac, DDS, PhD

Nobuhiro Hanadab', DDS, PhD

\begin{abstract}
Objectives : The evaluation of Mutans streptococci (MS) is one of the index for caries risk. Dentocult ${ }^{\top M}$ and $\mathrm{CRT}^{\mathrm{TM}}$ are commercial kits to detect and evaluate MS, conveniently. However, the evaluation of MS has also been carried out simply using an instruction manual. But the instruction manual is not easy to use for evaluation of MS. The aim of this study was to examine the utility of modified Mitis-Salivalius Bacitracin (MSB) agar medium compared with MSB agar medium and commercial kits, and to establish a convenient kit (mMSB-kit) using modified MSB agar.

Methods : The MS in stimulated saliva from 27 subjects were detected by MSB, modified MSB agar medium and commercial kits. Laboratory and clinically isolated strains of MS were similarly evaluated. The ratios of MS in detected bacteria were compared by ELISA.

Results : The scores using an mMSB-kit on the basis of modified MSB agar medium were tabulated. Saliva samples showed different levels of MS between culture methods and the commercial kit. Some samples which were full of MS were not detected by the commercial kit. The detection of MS by modified MSB agar medium and mMSB-kit were significantly higher when compared with MSB agar medium, $\mathrm{CRT}^{\mathrm{TM}},(\mathrm{P}<.01)$ and Dentocult $\mathrm{SM}^{\mathrm{TM}}(\mathrm{P}<.05)$.

Conclusion : The sensitivity for detection of MS is higher for modified MSB agar medium when compared with MSB agar medium. The mMSB-kit can be used simply, and can be an important contributor for the evaluation of MS as a caries risk factor. (Eur J Dent 2007;1:31-39)
\end{abstract}

Key words: Commercial kits; Culture methods; Streptococci mutans; Streptococcus sobrinus.

\section{INTRODUCTION}

Dental caries has a multifactorial etiology. It has been suggested to be triggered by three main factors: host, environment and bacteria. ${ }^{1,2}$ Mutans streptococci (MS) and lactobacilli are well known as cariogenic oral bacteria. ${ }^{3,4}$ MS including Streptococcus mutans (S. mutans) and Streptococcus sobrinus (S. sobrinus) are well known as a group of oral microorganisms which have virulence fac-

$\square$ a Department of Preventive Dentistry and Public Health, School of Dental Medicine, Tsurumi University, Japan.

${ }^{b}$ Department of Oral Health,

National Institute of Public Health, Japan.

Department of Operative Dentistry, School of Dentistry, Aichi Gakuin University, Japan.

$\square$ Corresponding author: Fusao Nishikawara,

Department of Preventive Dentistry and Public Health, School of Dental Medicine, Tsurumi University,

2-1-3 Tsurumi Tusrumi-ku Yokohama, 230-8501 Japan

Telephone: $+81-45-580-8379$

Fax: +81-45-573-9599

E-mail: fnishydayahoo.co.jp tors and which are harbored on the tooth surface within the oral biofilm. The key virulence factors are synthesized water insoluble glucan from sucrose, acidogenicity and acid tolerance..$^{5-7}$ Among the three factors described above, bacteria have been suggested to have the strongest effect on the prevalence or incidence of dental caries. . $^{8-10}$ Therefore, it is necessary to establish an accurate method for the detection and evaluation of these bacteria. Mitis-Salivarius Bacitracin (MSB) agar is the conventional culture medium and is known as a method to selectively detect MS. ${ }^{11}$ However, clinical studies suggest that MS are not detected in the patients with high levels of total number of Decayed, Missing and Filling teeth as DMF. In contrast, these bacteria are detected at high levels in subjects with no dental caries. ${ }^{12,13}$ These results show that the specificity of the test is not always high. ${ }^{14,15}$ Additionally, other bacteria also grow sometimes in this medium. Furthermore, to carry out conventional bacterial culture methods, ex- 
pensive equipment and facilities are needed. Dentocult $\mathrm{SM}^{\mathrm{TM}}$ and $\mathrm{CRT}^{\mathrm{TM}}$ are commercially available kits used in clinical or epidemiological studies and they are equally able to detect and evaluate MS, conveniently, at the chair side, without expensive equipment or facilities. ${ }^{16}$ The MSB agar medium has been used with Dentocult $\mathrm{SM}^{\mathrm{TM}}$ and $\mathrm{CRT}^{\mathrm{TM}}$. The results of detection of MS have been evaluated simply using the model chart in the instruction manual. However, the corresponding results of cultures and kits are not easy. Moreover, validity of evaluation for the model chart has scarcely been discussed. Recently, a natural genetic transformation has been revealed in mutans groups. This occurred through genetic variation, while other mutans streptococci may have acquired resistance to antibiotics. ${ }^{17,18}$ Ida et al ${ }^{19}$ modified MSB agar medium which improved the selective detection of MS by adding Gramicidin.Thus, the aim of our study was to examine the utility of modified MSB agar medium compared with MSB agar medium, Dentocult $\mathrm{SM}^{\mathrm{TM}}$ and $\mathrm{CRT}^{\mathrm{TM}}$ for detecting laboratory strains of $S$. mutans and S. sobrinus, MS in stimulated saliva samples. The clinical isolated strains of $S$. mutans and $S$. sobrinus were also carried out, because it has suggested $S$. mutans and $S$. sobrinus acquire the antibiotic-resistance by natural genetic transformation. In addition, we developed a convenient kit (mMSB-kit) using modified MSB agar medium and evaluated the utility of the modified MSB agar medium.

\section{MATERIALS AND METHODS}

\section{Bacterial strains}

Laboratory strains used in this study were 5 strains of $S$. mutans (S. mutans 8148, LM7, EM2, Ingbritt, OMZ 175) and 4 strains of $S$. sobrinus (S. sobrinus 6715, 33478, AHT, OMZ176). Bacterial cultures were stored at $-80^{\circ} \mathrm{C}$ in Brain Heart Infusion (BHI: Difco, Tokyo, JAPAN) broth containing 50\% glycerol (stock solution). These bacteria were obtained from ATCC, and stocked in the National Institute of Public Health in Japan. Clinically isolated strains were obtained from stimulated saliva samples. Samples were dispersed by vortexing (Model no. G560; Scientific Industries Inc., NY, USA) and diluted $\left(1 / 10^{2}\right.$ to $\left.1 / 10^{4}\right)$ into phosphate buffered saline (PBS). Following culturing on MSB agar medium, it was incubated at $37^{\circ} \mathrm{C}$ for 48 hours. Viable colonies were identified under a dissecting microscope. S. mutans or S. sobrinus were isolated from these plates in different proportions. They were distinguished by their distinctive clonal morphology. Clinically isolated strains were stored at $-20^{\circ} \mathrm{C}$ as stock solutions.

Study population, oral examination, and saliva sampling

The study population consisted of twenty-sev- en adult volunteers, 11 male and 16 female, who were in good physical condition and had good oral health. Mean age was $26.4 \pm 5.9$ years old (range: 17 to 39 years). Subjects were informed about the aim of this study well in advance and signed an informed consent form. Decayed, missing and teeth with fillings indices (number of DMF per adult) were recorded for each subject after oral examination. Five min, paraffin-stimulated whole saliva samples were obtained from subjects. Samples were immediately put on ice and transported to the laboratory.

\section{Culture method and condition}

The modified MSB agar medium is Mitis Salivarius agar (Difco, Tokyo, JAPAN) supplemented with 20\% sucrose (Wako Pure Chemicals Co., Osaka, JAPAN), 20 mg/ ml Yeast Extract (Becton Dickinson, MD, USA), $0.25 \cup$ Bacitracin (SIGMA, MO, USA), $10 \mathrm{mg} / \mathrm{ml}$ Colistin (Wako Pure Chemicals Co., Osaka, JAPAN), 10 mg/ ml Nalidixic Acid (Wako Pure Chemicals Co., Osaka, JAPAN), 4 mg/ $\mathrm{ml}$ Gramicidin (SIGMA, MO, USA) and 1\% tellurite solution. Then, mMSB-kits were developed using $5 \mathrm{ml}$ of modified MSB agar medium poured into a sterilized acrylic case $(1.5 \times 3 \times 7 \mathrm{~cm})$. For inoculation of MSB agar media and modified MSB agar media were inoculated using a spiral system (IUL, S. A., Torrent, SPAIN). The samples were dropped on Dentocult SM ${ }^{\top M}$ IOrion Diagnostica, Helsinki, Finland), CRT ${ }^{\mathrm{TM}}$ (VIVADENT Ets., Schaan, Liechtenstein) and mMSB-kit by syringe. After incubation at $37^{\circ} \mathrm{C}$ for 48 hours, visible colonies grown on these media were counted with the aid of a microscope (Model no. SMZ-10; Nicon, Tokyo, JAPAN). Counting was performed using the spiral systems counting grid. The estimation of MS counts to growth on media was regulated between 20 to 200 colonies. Colony counts were transformed logarithmically to $\log _{10} \mathrm{CFU} / \mathrm{ml}$. Detection limits of MS counts were $3.7 \log _{10} \mathrm{CFU} / \mathrm{ml}$ in this study. Scores using the Dentocult SM ${ }^{\mathrm{TM}}$ or $\mathrm{CRT}^{\mathrm{TM}}$ systems were evaluated using the instruction manual after a similar incubation.

\section{Identification of clinically isolated strains}

Clinically isolated strains were identified by polymerase chain reaction (PCR), and DNA extraction from $S$. mutans and S. sobrinus was done using DNeasy kits (Qiagen, Tokyo, JAPAN). Gene sequences were amplified with primers GTF-B, GTF-I and taq DNA polymerase (Premix Taq; Takara Bio Inc., Shiga, JAPAN). Reaction mixtures and PCR cycles were as previously described. ${ }^{20,21}$ The sequences of primers used in this study were GTFB 5'-ACTACACTTTCGGTGGCTTGG-3' for $S$. mutans and GTF-I 5'-GATAACTACCTGACAGCTGACT-3' for S. sobrinus. Primer GTF-B was designed to amplify a 517 bp DNA fragment of $g t f B$ sequence of $S$. mu- 
tans. Primer GTF-I was designed to amplify a 712 bp DNA fragment of the gtfl sequence of $S$. sobrinus. The amplification was performed in a thermocycler (Takara Bio Inc., Shiga, JAPAN) with an initial denaturation at $95^{\circ} \mathrm{C}$ for $5 \mathrm{~min}$, followed by 40 cycles of denaturation $\left(95^{\circ} \mathrm{C}, 30 \mathrm{sec}\right)$, annealing $\left(59^{\circ} \mathrm{C}, 30 \mathrm{sec}\right)$ and extension $\left(72^{\circ} \mathrm{C}, 1 \mathrm{~min}\right)$. The final extension step was at $72^{\circ} \mathrm{C}$ for $7 \mathrm{~min}$. The PCR products were resolved by electrophoresis through $1.8 \%$ TBE agarose gels with $0.5 \mu \mathrm{g} / \mathrm{ml}$ ethidium bromide. Gels were photographed under UV trans illuminator (Funakoshi, Tokyo, JAPAN).

Evaluation of laboratory strains and clinical isolated strains

Laboratory strains and clinically isolated strains of $S$. mutans and $S$. sobrinus were cultured in $\mathrm{BHI}$ broth and incubated at $37^{\circ} \mathrm{C}$ for 18 hours. Following incubation, bacterial cultures were centrifuged (2500 rpmx $20 \mathrm{~min}$ ), washed, and adjusted, using PBS, to an optical density (OD540) of 1.0. For detection of MS, concentrated bacterial suspensions were serially diluted from $1 / 10$ to $1 / 10^{4}$ with PBS and inoculated on Dentocult SM ${ }^{\mathrm{TM}}, \mathrm{CRT}^{\mathrm{TM}}$, MSB agar medium, modified MSB agar medium or BHI supplemented 1.5\% agar (Difco, Tokyo, JAPAN) as a control plate. Each culture method and evaluation method was carried out similarly for clinical samples.

\section{Ratio of cariogenic bacteria}

For detection of $S$. mutans and $S$. sobrinus, total streptococci on each medium were calculated by Enzyme Linked Immunosorbent Assay (ELISA). The colonies were isolated in each medium for four typical subjects who showed different values in this study for detection of $S$. mutans and $S$. sobrinus by Dentocult SM ${ }^{\mathrm{TM}}, \mathrm{CRT}^{\mathrm{TM}}$ and MSB agar medium methods. Then, the isolated colonies were inoculated into 24 well microtiter plates (Sumitomo Bakelite, Tokyo JAPAN) in BHI broth. Following incubation at $37^{\circ} \mathrm{C}$ for 24 hours, the bacterial cells were harvested by centrifugation (2500 rpmx 20 min) and washed twice with PBS. For the ELISA, 96 well microtiter plates (Sumitomo Bakelite, Tokyo JAPAN) were coated with each bacteria solution and coating buffer solution for 18 hours at $37^{\circ} \mathrm{C}$. After drying the plate, it was washed with PBS containing $0.1 \%$ Tween 20 (PBST) and blocked with $1 \%$ skim milk in PBST for $1 \mathrm{~h}$ at $37^{\circ} \mathrm{C}$. Excess milk was removed and the plate was washed twice with PBST. Then the first antibodies -IH5-H4-C6 for $S$. mutans and IG6-A3-E4 for S. sobrinus - were added to the wells and incubated for 1 hour at $37^{\circ} \mathrm{C}$. The wells were then washed twice with PBST and further incubated for an hour at $37^{\circ} \mathrm{C}$ with alkaline phosphatase-conjugated affinity purified goat anti mouse IgG + IgM (Jackson Immuno Research Laboratories, PHL, USA). After washing twice with PBST, bound antibodies were detected by addition of disodium nitrophenyl phosphate hexahydrate (Wako Pure Chemicals Co., Osaka, JAPAN) for 30 minutes at $37^{\circ} \mathrm{C}$. The absorbance at $405 \mathrm{~nm}$ was measured with a micro-plate reader (MPR: Toso, Tokyo, JAPAN).

\section{Estimation of MS by mMSB-kit}

Four scores for detection of MS using the mMSB-kit were defined as follows: a score of 3 : $>6 \log _{10} \mathrm{CFU} / \mathrm{ml}$, score 2: 6-5 $\log _{10} \mathrm{CFU} / \mathrm{ml}$, score $0-1:<5 \log _{10} \mathrm{CFU} / \mathrm{ml}$. The scores were based on epidemiological studies for cariogenic bacteria

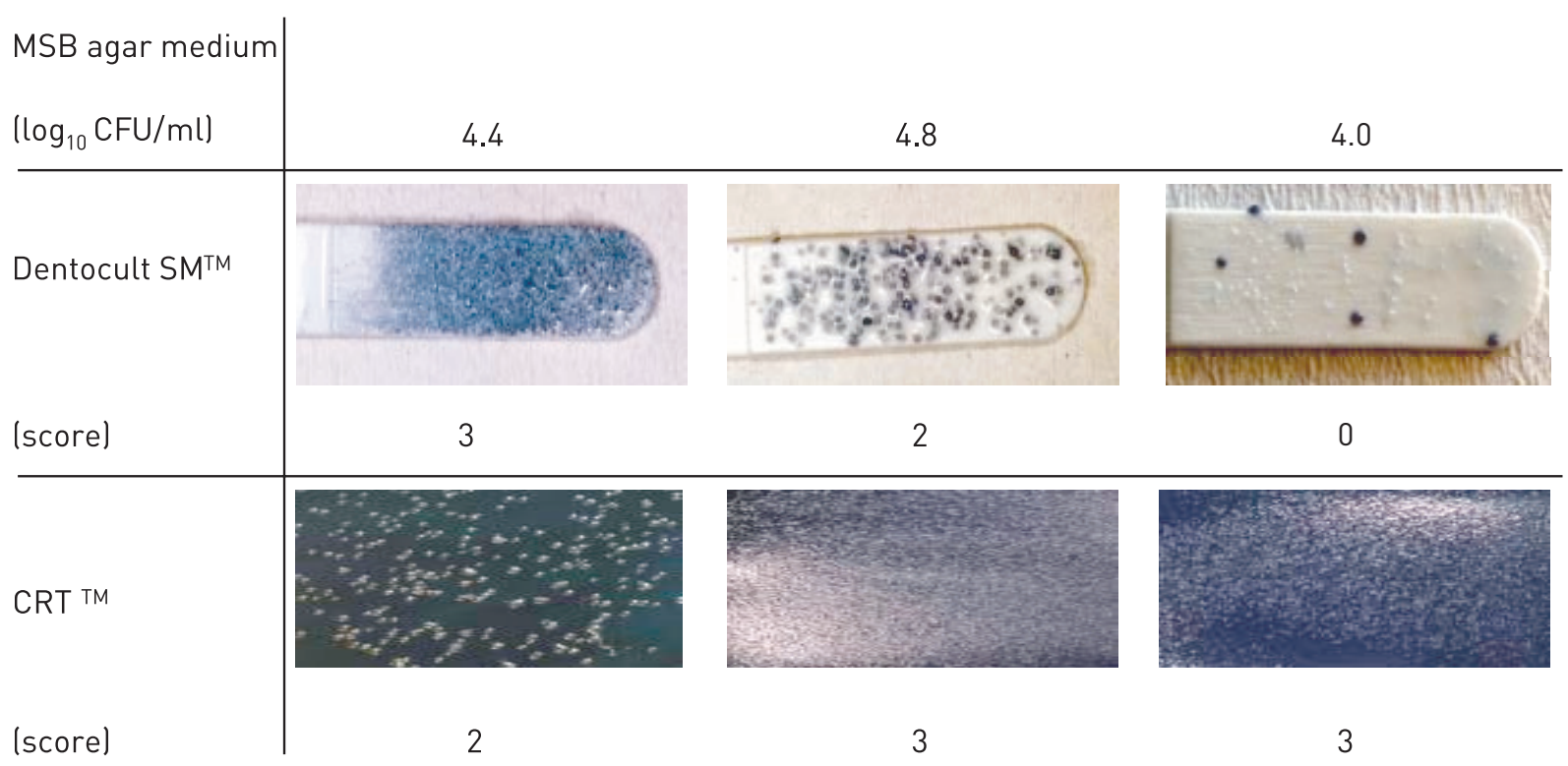

Figure 1 . Difference in the detection of MS comparing score or value of MSB agar medium, Dentocult $\mathrm{SM}^{\mathrm{TM}}$ and CRT ${ }^{\mathrm{TM}}$. 
and experiments on dental caries. ${ }^{22-25}$ Data on the detection of MS by Dentocult SM ${ }^{\mathrm{TM}}, \mathrm{CRT}^{\mathrm{TM}}$ and MSB agar medium were confirmed by mMSB-kit and modified MSB agar medium. After 2 days, saliva samples were again collected from subjects, and cultured using the mMSB-kit and modified MSB agar medium. Detection of MS by mMSB-kit was evaluated and compared with estimates for the modified MSB agar medium.

\section{Statistical analysis}

Three replicates were done for each concentration of the tested extracts for all assays. Each value represents the mean \pm standard deviation for assays. Correlations for the detection of MS on MSB agar medium, Dentocult SM ${ }^{\mathrm{TM}}$ and $\mathrm{CRT}^{\mathrm{TM}}$ were analyzed using Spearman's rho. The level of significance for all statistical tests was set at $\mathrm{P}<.05$ Differences in detection of MS were analyzed using the Mann-Whitney $U$ test.

\section{RESULTS}

\section{Clinical samples}

All subjects who participated in this study were healthy and without any chronic disease or daily intake of medicines. The characteristics of the subjects and the detection of MS by MSB agar medium, modified MSB agar medium, Dentocult $\mathrm{SM}^{\mathrm{TM}}$ and $\mathrm{CRT}^{\mathrm{TM}}$ are shown in Table 1. Experience of dental caries was as follows: number of filled teeth ranged from $0-27$, missing teeth from $0-2$, decayed teeth 0 (by oral examination). Figure 1 summarizes the estimation of MS which showed the different corresponding values or scores of MSB agar plate, Dentocult SM ${ }^{\mathrm{TM}}$ and $\mathrm{CRT}^{\mathrm{TM}}$ for the three of nine subjects. Levels of MS were compared among MSB agar medium and Dentocult $\mathrm{SM}^{\mathrm{TM}}$ or $\mathrm{CRT}^{\mathrm{TM}}$ and this is shown in Figure $2 \mathrm{a}-\mathrm{b}$. There was a positive association between MSB agar medium and Dentocult $\mathrm{SM}^{\mathrm{TM}}(\mathrm{P}<.05, \mathrm{rs}=0.53)$, whereas MSB agar medium and $C R T^{\mathrm{TM}}$ showed no correlation $(P<.05, r s=0.30)$.

\section{Estimation of cariogenic bacteria}

For clinical strains, we evaluated MS from 9 subjects and for 7 strains of $S$. mutans and 2 strains of $S$. sobrinus. Table 2a-c summarizes the detection of $S$. mutans and $S$. sobrinus in laboratory and clinically isolated strains with MSB agar medium, modified MSB agar medium, BHI agar medium, Dentocult $S M^{\mathrm{TM}}$ and $\mathrm{CRT}^{\mathrm{TM}}$. Inconsistent results for MS detection were observed for the conventional

Table 1. Characteristics of subjects who participated in this study.

\begin{tabular}{|c|c|c|c|c|c|c|c|c|c|}
\hline \multirow[b]{2}{*}{ No } & \multirow[b]{2}{*}{ Age } & \multirow[b]{2}{*}{$\mathrm{D}$} & \multicolumn{3}{|c|}{ Experience of caries } & \multicolumn{2}{|c|}{$\log _{10} \mathrm{CFU} / \mathrm{ml}$} & \multicolumn{2}{|c|}{ Score } \\
\hline & & & $M$ & $\mathrm{~F}$ & DMF & MSB agar & modified MSB agar & Dentocult SM ${ }^{\top M}$ & $\mathrm{CRT}^{\mathrm{TM}}$ \\
\hline 1 & 27 & 0 & 0 & 21 & 21 & 5.5 & 5.3 & 2 & 2 \\
\hline 2 & 21 & 0 & 0 & 11 & 11 & 5.2 & 5.2 & 3 & 3 \\
\hline 3 & 22 & 0 & 0 & 7 & 7 & - & - & 1 & 1 \\
\hline 4 & 30 & 0 & 1 & 10 & 11 & 5.1 & 5.1 & 3 & 3 \\
\hline 5 & 27 & 0 & 0 & 10 & 10 & - & - & 2 & 2 \\
\hline 6 & 25 & 0 & 0 & 6 & 6 & 4.2 & 4.0 & 3 & 3 \\
\hline 7 & 21 & 0 & 0 & 1 & 1 & 5.0 & 5.1 & 1 & 1 \\
\hline 8 & 21 & 0 & 0 & 3 & 3 & 5.0 & 4.8 & 1 & 1 \\
\hline 9 & 26 & 0 & 1 & 13 & 14 & 3.9 & 3.9 & 2 & 2 \\
\hline 10 & 27 & 0 & 1 & 20 & 21 & 4.4 & 4.4 & 3 & 2 \\
\hline 11 & 24 & 0 & 0 & 12 & 12 & 4.1 & 4.1 & 1 & 1 \\
\hline 12 & 28 & 0 & 0 & 9 & 9 & 5.5 & 5.5 & 3 & 3 \\
\hline 13 & 22 & 0 & 0 & 9 & 9 & 6.1 & 6.0 & 3 & 3 \\
\hline 14 & 20 & 0 & 1 & 14 & 15 & 5.1 & 5.1 & 2 & 3 \\
\hline 15 & 21 & 0 & 0 & 14 & 14 & 4.8 & 4.8 & 2 & 3 \\
\hline 16 & 17 & 0 & 2 & 12 & 14 & - & - & 0 & 0 \\
\hline 17 & 39 & 0 & 0 & 5 & 5 & - & - & 2 & 3 \\
\hline 18 & 30 & 0 & 1 & 10 & 11 & - & - & 0 & 2 \\
\hline 19 & 22 & 0 & 0 & 1 & 1 & 4.0 & 4.0 & 0 & 3 \\
\hline 20 & 30 & 0 & 0 & 13 & 13 & - & - & 1 & 3 \\
\hline 21 & 38 & 0 & 0 & 27 & 27 & 4.3 & 4.3 & 0 & 3 \\
\hline 22 & 34 & 0 & 0 & 8 & 8 & - & - & 0 & 3 \\
\hline 23 & 39 & 0 & 0 & 9 & 9 & 5.6 & 5.6 & 3 & 3 \\
\hline 24 & 26 & 0 & 0 & 5 & 5 & 5.8 & 5.5 & 1 & 1 \\
\hline 25 & 21 & 0 & 0 & 0 & 0 & - & - & 1 & 1 \\
\hline 26 & 28 & 0 & 0 & 8 & 8 & - & - & 0 & 0 \\
\hline 27 & 27 & 0 & 0 & 5 & 5 & 3.9 & 4.1 & 0 & 0 \\
\hline
\end{tabular}

- indicates under the detection limit

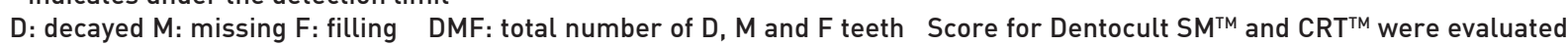
using the model chart in the instruction manual. 
culture methods and the commercial kit. Also, a few bacteria were not detected by the commercial kit.

\section{Ratio of cariogenic bacteria}

Figure 3 summarizes the ratio of cariogenic bacteria to total streptococci when antibodies for $S$. mutans and $S$. sobrinus and identification with ELISA were used. Levels of cariogenic bacteria in each subject analyzed with MSB agar medium, modified MSB agar medium, commercialized kits and mMSB-kit for detection of $S$. mutans and $S$. sobrinus. Modified MSB agar medium and mMSBkit were significantly higher when compared with
MSB agar medium, $\mathrm{CRT}^{\mathrm{TM}}(\mathrm{P}<.01)$ and Dentocult $\mathrm{SM}^{\mathrm{TM}}(\mathrm{P}<.05)$. There was no significant difference between results for modified MSB agar medium and mMSB-kit.

\section{Evaluation of MS by mMSB-kit}

The mMSB-kit was compared with modified MSB medium. The typical classification using 4 scores for detection of $S$. mutans and $S$. sobrinus are shown in Figure 4. The typical class score 3 corresponds to about $6 \log _{10} \mathrm{CFU} / \mathrm{ml}$, score 2 corresponds to between $5-6 \log _{10} \mathrm{CFU} / \mathrm{ml}$, and score 0-1 corresponds to $<5 \log _{10} \mathrm{CFU} / \mathrm{ml}$. Saliva of 25 subjects was again collected and cultured by

Table 2a. Detection of laboratory strains of $S$. mutans.

\begin{tabular}{|c|c|c|c|c|c|c|}
\hline \multirow[b]{2}{*}{$\begin{array}{l}\text { S. mutans } \\
\text { laboratory strains }\end{array}$} & \multirow[b]{2}{*}{ Dilution } & \multicolumn{3}{|c|}{$\log _{10} \mathrm{CFU} / \mathrm{ml}$ (SD) } & \multicolumn{2}{|l|}{ Score } \\
\hline & & MSB agar & modified MSB agar & $\mathrm{BHI}$ agar & Dentocult SM ${ }^{\top M}$ & $\mathrm{CRT}^{\mathrm{TM}}$ \\
\hline \multirow{3}{*}{8148} & $1 / 10^{2}$ & $6.1 \pm 0.15$ & $6.3 \pm 0.3$ & $6.4 \pm 0.1$ & 3 & 2 \\
\hline & $1 / 10^{3}$ & $5.2 \pm 0.1$ & $5.1 \pm 0.12$ & $5.2 \pm 0.15$ & 2 & 1 \\
\hline & $1 / 10^{4}$ & $4.2 \pm 0.2$ & $4.0 \pm 0.25$ & $4.3 \pm 0.21$ & 2 & 1 \\
\hline \multirow{3}{*}{ LM7 } & $1 / 10^{2}$ & $5.4 \pm 0.12$ & $6.2 \pm 0.15$ & $6.2 \pm 0.12$ & 3 & 0 \\
\hline & $1 / 10^{3}$ & $4.4 \pm 0.15$ & $5.1 \pm 0.06$ & $5.1 \pm 0.21$ & 1 & 0 \\
\hline & $1 / 10^{4}$ & - & $4.2 \pm 0.21$ & $4.2 \pm 0.27$ & 1 & 0 \\
\hline \multirow{3}{*}{ EM2 } & $1 / 10^{2}$ & $6.7 \pm 0.15$ & $6.2 \pm 0.25$ & $6.7 \pm 0.21$ & 2 & 2 \\
\hline & $1 / 10^{3}$ & $5.6 \pm 0.27$ & $5.1 \pm 0.15$ & $5.6 \pm 0.25$ & 1 & 1 \\
\hline & $1 / 10^{4}$ & $4.4 \pm 0.15$ & $4.1 \pm 0.06$ & $4.4 \pm 0.1$ & 1 & 0 \\
\hline \multirow{3}{*}{ Ingbritt } & $1 / 10^{2}$ & $6.6 \pm 0.1$ & $6.9 \pm 0.12$ & $7.2 \pm 0.25$ & 2 & 0 \\
\hline & $1 / 10^{3}$ & $5.6 \pm 0.1$ & $5.7 \pm 0.21$ & $6.0 \pm 0.21$ & 0 & 0 \\
\hline & $1 / 10^{4}$ & $4.7 \pm 0.15$ & $3.9 \pm 0.06$ & $4.9 \pm 0.06$ & 0 & 0 \\
\hline \multirow{3}{*}{ OMZ175 } & $1 / 10^{2}$ & $5.7 \pm 0.12$ & $5.8 \pm 0.17$ & $6.7 \pm 0.27$ & 1 & 0 \\
\hline & $1 / 10^{3}$ & $4.6 \pm 0.1$ & $4.7 \pm 0.21$ & $5.5 \pm 0.21$ & 0 & 0 \\
\hline & $1 / 10^{4}$ & - & - & $4.4 \pm 0.15$ & 0 & 0 \\
\hline
\end{tabular}

Each value represents the mean \pm standard deviation for assays performed three times. Indicates under the detection limit.

Table 2 b. Detection of laboratory strains of S.sobrinus.

\begin{tabular}{lcccccc}
\hline & \multicolumn{3}{c}{$\log _{10} \mathrm{CFU} / \mathrm{ml}$ (SD) } & \multicolumn{2}{c}{ Score } \\
\hline $\begin{array}{l}\text { S. sobrinus } \\
\text { laboratory strains }\end{array}$ & Dilution & MSB agar & modified MSB agar & BHI agar & Dentocult SM ${ }^{\text {TM }}$ & CRT $^{\text {TM }}$ \\
\hline \multirow{3}{*}{6715} & $1 / 10^{2}$ & $5.1 \pm 0.06$ & $5.4 \pm 0.2$ & $5.6 \pm 0.1$ & 2 & 0 \\
& $1 / 10^{3}$ & $4.1 \pm 0.12$ & $4.3 \pm 0.15$ & $4.8 \pm 0.1$ & 1 & 0 \\
\hline & $1 / 10^{4}$ & - & $3.8 \pm 0.12$ & $4.0 \pm 0.21$ & 0 & 0 \\
33478 & $1 / 10^{2}$ & $6.2 \pm 0.2$ & $6.1 \pm 0.12$ & $6.3 \pm 0.2$ & 2 & 2 \\
& $1 / 10^{3}$ & $5.2 \pm 0.2$ & $5.1 \pm 0.12$ & $5.0 \pm 0.46$ & 2 & 2 \\
AHT & $1 / 10^{4}$ & $4.4 \pm 0.15$ & $4.1 \pm 0.1$ & $4.3 \pm 0.15$ & 1 & 1 \\
\hline & $1 / 10^{2}$ & $6.2 \pm 0.1$ & $6.1 \pm 0.15$ & $6.4 \pm 0.21$ & 3 & 3 \\
OMZ176 & $1 / 10^{3}$ & $5.3 \pm 0.14$ & $5.1 \pm 0.1$ & $5.4 \pm 0.15$ & 3 & 1 \\
& $1 / 10^{4}$ & $3.9 \pm 0.46$ & $4.1 \pm 0.21$ & $4.3 \pm 0.06$ & 1 & 0 \\
\hline
\end{tabular}

Each value represents the mean \pm standard deviation for assays performed three times.

Indicates under the detection limit. 
Table 2c. Detection of clinical isolated strains of $S$. mutans and S. sobrinus .

\begin{tabular}{|c|c|c|c|c|c|c|c|}
\hline \multirow{2}{*}{\multicolumn{2}{|c|}{$\begin{array}{c}\text { Clinically isolated } \\
\text { strains }\end{array}$}} & \multirow{2}{*}{ Dilution } & \multicolumn{3}{|c|}{$\log _{10} \mathrm{CFU} / \mathrm{ml}$ (SD) } & \multicolumn{2}{|l|}{ Score } \\
\hline & & & MSB agar & modified MSB agar & $\mathrm{BHI}$ agar & Dentocult SM ${ }^{\top \mathrm{M}}$ & $\mathrm{CRT}^{\mathrm{TM}}$ \\
\hline \multirow{9}{*}{ S. mutans } & \multirow{3}{*}{ YS } & $1 / 10^{1}$ & $6.1 \pm 0.15$ & $6.4 \pm 0.26$ & $6.5 \pm 0.1$ & 3 & 1 \\
\hline & & $1 / 10^{2}$ & $5.2 \pm 0.1$ & $5.3 \pm 0.15$ & $5.4 \pm 0.21$ & 3 & 0 \\
\hline & & $1 / 10^{3}$ & $4.2 \pm 0.2$ & $4.7 \pm 0.25$ & $4.5 \pm 0.15$ & 2 & 0 \\
\hline & \multirow{3}{*}{ MM } & $1 / 10^{1}$ & $5.4 \pm 0.12$ & $5.6 \pm 0.1$ & $6.3 \pm 0.1$ & 3 & 0 \\
\hline & & $1 / 10^{2}$ & $4.4 \pm 0.15$ & $4.5 \pm 0.06$ & $5.5 \pm 0.12$ & 2 & 0 \\
\hline & & $1 / 10^{3}$ & - & - & $4.4 \pm 0.06$ & 1 & 0 \\
\hline & \multirow{3}{*}{ FN } & $1 / 10^{1}$ & $6.7 \pm 0.15$ & $6.8 \pm 0.15$ & $6.7 \pm 0.1$ & 3 & 1 \\
\hline & & $1 / 10^{2}$ & $5.6 \pm 0.27$ & $5.6 \pm 0.26$ & $5.8 \pm 0.06$ & 3 & 0 \\
\hline & & $1 / 10^{3}$ & $4.4 \pm 0.15$ & $4.5 \pm 0.21$ & $4.7 \pm 0.1$ & 2 & 0 \\
\hline \multirow{6}{*}{ S. sobrinus } & \multirow{3}{*}{ NY } & $1 / 10^{1}$ & $6.6 \pm 0.1$ & $6.6 \pm 0.1$ & $6.7 \pm 0.06$ & 3 & 0 \\
\hline & & $1 / 10^{2}$ & $5.6 \pm 0.1$ & $5.8 \pm 0.12$ & $5.7 \pm 0.12$ & 2 & 0 \\
\hline & & $1 / 10^{3}$ & $4.7 \pm 0.15$ & $4.9 \pm 0.06$ & $4.8 \pm 0.15$ & 2 & 0 \\
\hline & \multirow{3}{*}{$\mathrm{SH}$} & $1 / 10^{1}$ & $5.7 \pm 0.12$ & $5.9 \pm 0.1$ & $6.3 \pm 0.21$ & 2 & 1 \\
\hline & & $1 / 10^{2}$ & $4.6 \pm 0.1$ & $4.7 \pm 0.2$ & $5.1 \pm 0.12$ & 1 & 0 \\
\hline & & $1 / 10^{3}$ & - & $3.8 \pm 0.12$ & $4.0 \pm 0.1$ & 0 & 0 \\
\hline
\end{tabular}

Each value represents the mean \pm standard deviation for assays performed three times.

- indicates under the detection limit.

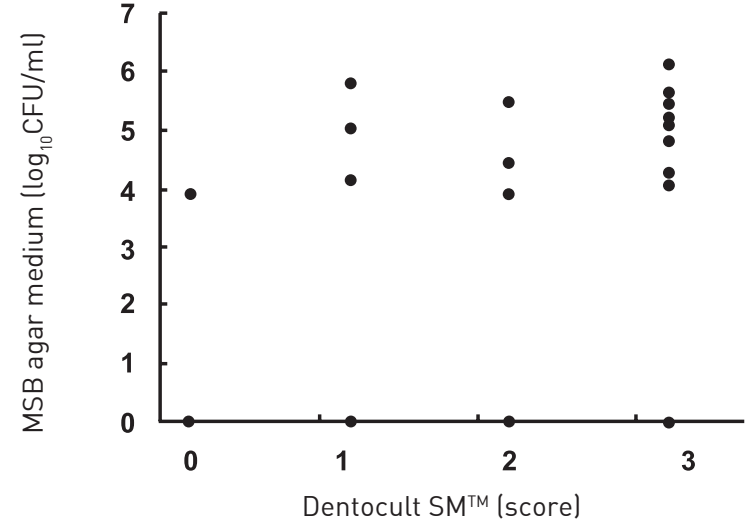

Figure 2a. Detection of MS was compared between MSB agar medium and Dentocult $\mathrm{SM}^{\mathrm{TM}}$.

The detection limits for MS on MSB agar plates were 0 .

Score for Dentocult $\mathrm{SM}^{\mathrm{TM}}$ and $\mathrm{CRT}^{\mathrm{TM}}$ are as follows,

score 3: $>6 \log _{10} \mathrm{CFU} / \mathrm{ml}$, score 2: $6-5 \log _{10} \mathrm{CFU} / \mathrm{ml}$, score $0-1$ : $<5 \log _{10} \mathrm{CFU} / \mathrm{ml}$.

There was a positive association between MSB agar medium and Dentocult $\mathrm{SM}^{\mathrm{TM}}(\mathrm{P}<.05, \mathrm{rs}=0.53)$,

whereas MSB agar medium and $\mathrm{CRT}^{\mathrm{TM}}$ showed no correlation $(P<.05, r s=0.30)$ by Spearman.

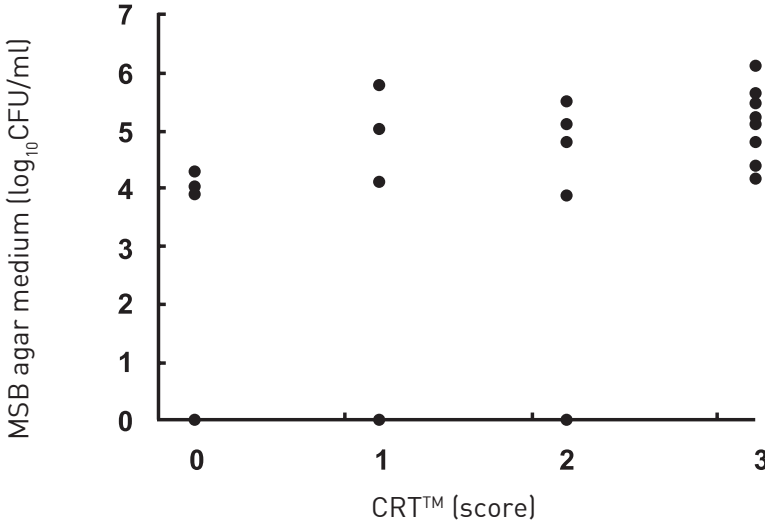

Figure $2 b$. Detection of MS was compared between MSB agar medium and $\mathrm{CRT}^{\mathrm{TM}}$.

The detection limits for MS on MSB agar plates were 0 .

Score for Dentocult SM ${ }^{\mathrm{TM}}$ and $\mathrm{CRT}^{\mathrm{TM}}$ are as follows,

score 3: $>6 \log _{10} \mathrm{CFU} / \mathrm{ml}$, score 2: 6-5 $\log _{10} \mathrm{CFU} / \mathrm{ml}$, score 0-1: $<5 \log _{10} \mathrm{CFU} / \mathrm{ml}$.

There was a positive association between MSB agar medium and Dentocult $\mathrm{SM}^{\mathrm{TM}}(\mathrm{P}<.05, \mathrm{rs}=0.53)$,

whereas MSB agar medium and $C R T^{T M}$ showed no correlation $(P<.05, r s=0.30)$ by Spearman.

Table 3. Ratios of $S$. mutans and S. sobrinus calculated by different methods.

\begin{tabular}{|c|c|c|c|c|c|}
\hline & Dentocult SM ${ }^{\top \mathrm{M}}$ & $\mathrm{CRT}^{\mathrm{TM}}$ & MSB agar & modified MSB agar & mMSB-kit \\
\hline Dentocult SM ${ }^{\mathrm{TM}}$ & & $\mathrm{N}$ & $\mathrm{N}$ & $*$ & $*$ \\
\hline $\mathrm{CRT}^{\mathrm{TM}}$ & $\mathrm{N}$ & & $\mathrm{N}$ & $* *$ & $* *$ \\
\hline MSB agar & $\mathrm{N}$ & $\mathrm{N}$ & & $* *$ & $* *$ \\
\hline modifiedMSB agar & $*$ & $* *$ & $* *$ & & $\mathrm{~N}$ \\
\hline mMSB-kit & $*$ & $* *$ & $* *$ & $\mathrm{~N}$ & \\
\hline
\end{tabular}

* : $\mathrm{P}<.05$ (Mann-Whitney test) $\quad{ }^{* *}: \mathrm{P}<.01$ (Mann-Whitney test) $\quad \mathrm{N}$ : not significantly different 


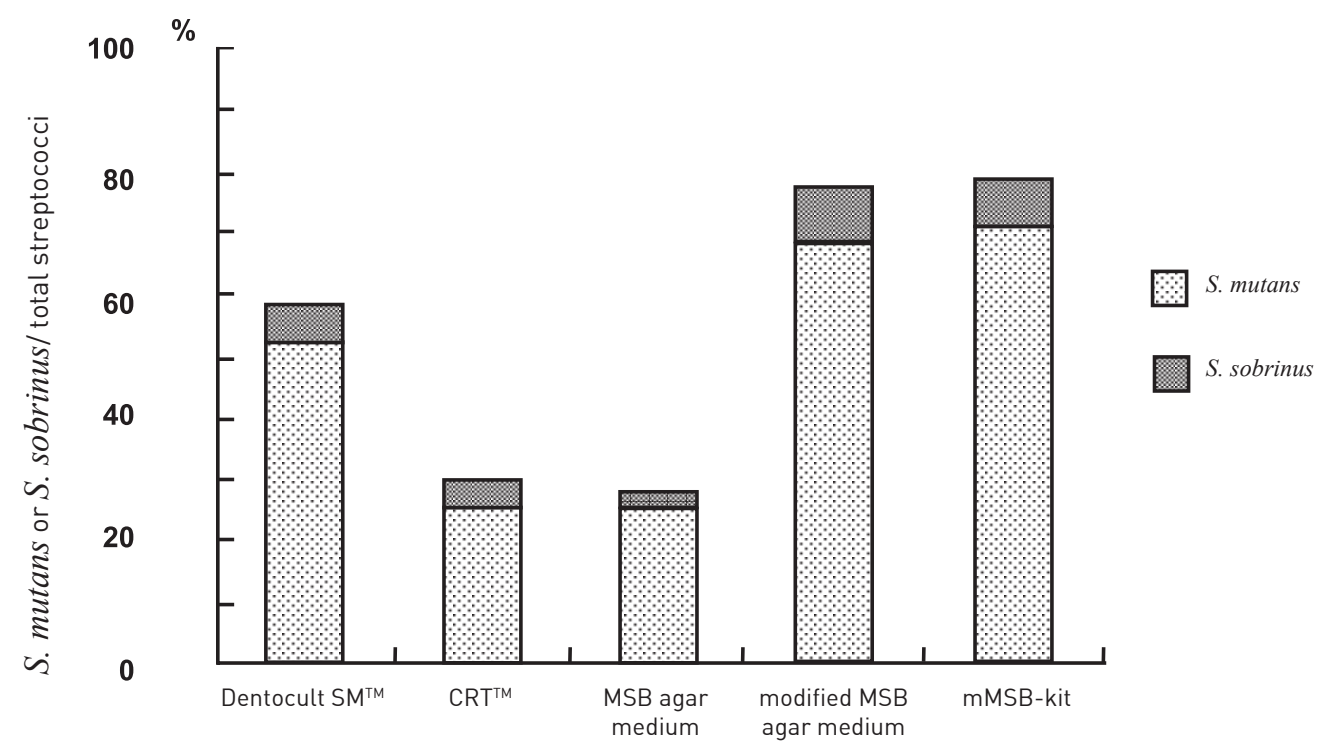

Figure 3. Ratios of $S$. mutans and $S$. sobrinus calculated by different methods.

Differences in the ratio of $S$. mutans and S. sobrinus were different for modified MSB agar medium and mMSB-kit compared to the Dentocult $S M^{\top M}\left(P<.05\right.$ : Mann-Whitney test), $C R T^{T M}$ and MSB agar medium ( $P<.01$ : Mann-Whitney test). However, differences in the S. mutans and $S$. sobrinus ratios were not significant between the Dentocult $\mathrm{SM}^{\mathrm{TM}}$, CRT ${ }^{\mathrm{TM}}$ and MSB agar medium.

mMSB-kit and results were compared with those for modified MSB agar medium (Figure 5). There was a positive association between modified MSB agar medium and mMSB-kit $(\mathrm{P}<.01, \mathrm{rs}=0.84)$.

\section{DISCUSSION}

Dental caries is a multifactorial disease which is complicated by host environmental and bacterial factors. At the present time, it is necessary to be aware of these factors and to establish pre-
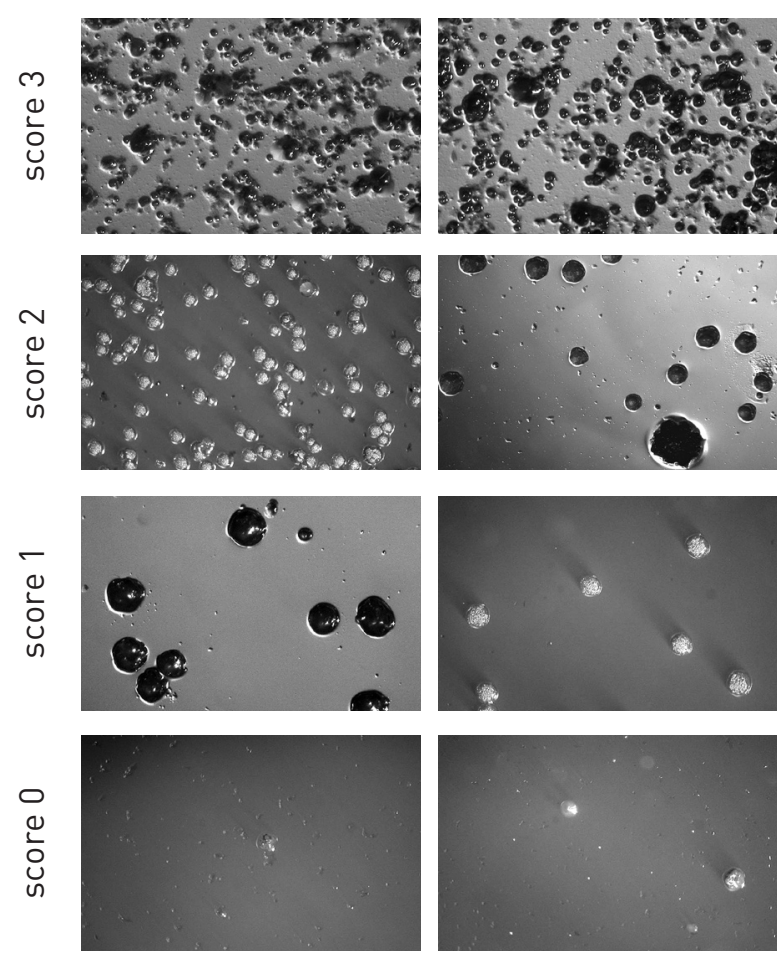

Figure 4 . Classification score for detection of $S$. $m u$ tans and $S$. sobrinus by mMSB-kit. ventive programs taking all of these factors into account. It is especially important to comprehend the contribution of bacteria, which has been suggested to be the most prominent factor in dental caries. ${ }^{26-30}$ In our study, each mMSB-kit was made from modified MSB agar medium which increased detection of $S$. mutans and $S$. sobrinus. This kit was compared with MSB agar medium, modified agar medium, Dentocult SM ${ }^{\mathrm{TM}}$ and $\mathrm{CRT}^{\mathrm{TM}}$ in the analysis of saliva samples from subjects, from laboratory specimens, and from clinically isolated strains of $S$. mutans and S. sobrinus. A difference was recognized for several methods. Accurate evaluation can not always be obtained as a different result is obtained by conventional culture methods and by commercial kits. In fact, it is possible to evalu-

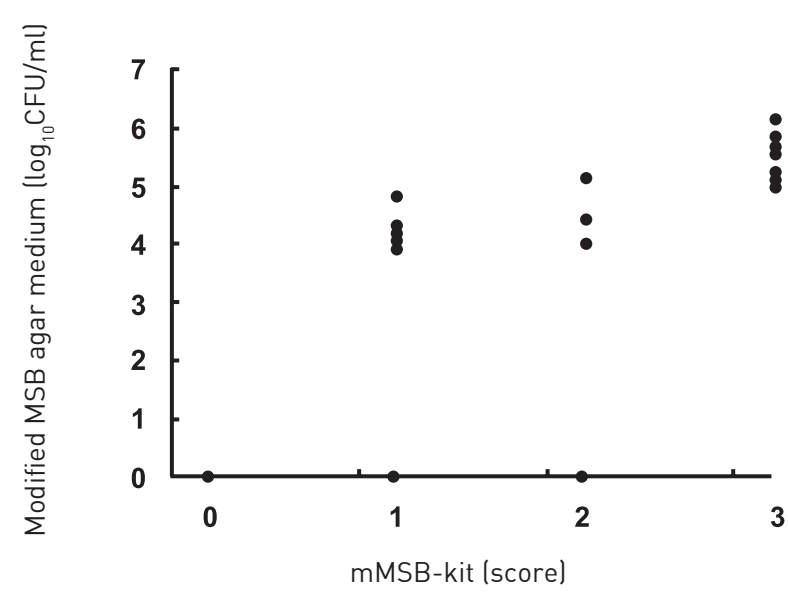

Figure 5. Comparison between mMSB-kit and modified MSB agar medium for detection of MS.

There was a positive association between modified MSB agar medium and mMSB-kit $(P<.01, r s=0.84)$ by Spearman. 
ate a patient as being at high risk for dental caries because of an "apparent" large amount of bacteria is detected by commercial kits. In contrast, it is possible to evaluate a patient as being at low risk of dental caries because of the existence of bacteria which were not detected. In these cases, it has been ungraspable to evaluate the bacteria factor accurately. One reason for the different results may be that one strain of $S$. sobrinus does not grow on MSB agar medium due to lack of tolerance to Bacitracin. ${ }^{14,15,31}$ It has been reported that the virulence of $S$. sobrinus is equal to or higher than that of $S$. mutans. As for synergy effect, the caries risk is increased more for a single infection of $S$. mutans than for a mixed infection of $S$. mutans and S. sobrinus. ${ }^{32-35}$ Epidemiological studies of the relationship between the experience of dental caries and caries risk report that the caries risk of subjects who possess both $S$. mutans and $S$. sobrinus is higher than that for subjects possessing only $S$. mutans or only S. sobrinus. ${ }^{36,37}$ Therefore, to evaluate caries risk in terms of the bacterial factor, it is important to evaluate not only the total amount of $S$. mutans and $S$. sobrinus, but also the amounts of each. Several methods for detection and identification of $S$. mutans and $S$. sobrinus have been reported for selective media and subsequent biochemical or serological tests ${ }^{11,38-41}$ and DNA probe methods. ${ }^{42,43}$ Recently, selective culture techniques for $S$. sobrinus have been reported. ${ }^{44}$ The modified MSB agar medium also uses Bacitracin, but to prevent tolerance of MS to Bacitracin, Colistin, Nalidixic Acid and Gramicidin are added. Furthermore, Yeast Extract is added to promote cell growth. Several methods were used to identify $S$. mutans and S. sobrinus by ELISA. The modified MSB agar medium showed significantly higher levels of $S$. mutans and S. sobrinus when compared with conventional culture methods of MSB agar medium and commercial kits. The mMSB-kit was used to modify the MSB agar medium, which also showed high levels of detection of $S$. mutans and $S$. sobrinus. Detection of MS by modified MSB agar medium is reproducible. The formation of commercial kits made using MSB agar medium are different from conventional formation of MSB agar medium. The composition of conventional MSB agar medium is adjusted for Bacitracin and sucrose by $0.2 \mathrm{U}$ and $20 \%$ respectively. In contrast, Dentocult SM ${ }^{\mathrm{TM}}$ had a consistency of $0.26 \mathrm{U}$ and $30 \%$, and $\mathrm{CRT}^{\mathrm{TM}}$ a consistency of sucrose $41 \% .{ }^{16,45}$ It has been reported that growth of $S$. mutans and $S$. sobrinus is inhibited by no less than $0.3 \mathrm{U}$ of Bacitracin and no less than $30 \%$ sucrose. $^{16,46}$ It has thought of as loss of detection of MS by commercial kit for effects of these compositions. Natural genetic transformation is a process by which bacteria are able to take up and integrate exogenous free DNA from their environment. This process enables the recipient organisms to acquire novel genes or heritable traits, thereby promoting the emergence of antibiotic resistance and genetic variation and the rapid evolution of virulence. The rapid emergence and spread of antibiotic resistance is probably the most commonly recognized manifestation of this process. ${ }^{17,18}$ The MSB agar medium is possible that detection of $S$. mutans and $S$. sobrinus selectively to show the resistance of Bacitracin all but a few of $S$. sobrinus. For the appearance of resistant bacteria, non-MS have the possibility to evaluate as cariogenic bacteria in Japan which has prescribed for large quantities antibiotic. Previous studies have reported that salivary levels of $S$. $m u$ tans can be used to predict caries risk. $S$. mutans counts $>6 \log _{10}$ CFU/ml in saliva indicates a high caries risk. ${ }^{47,48}$ Meanwhile, the odds ratio of detection of MS by commercial kit lodds ratio of scores 1,2 , and 3 were $1.4,6.5$ and 8.9 , respectivelyl is higher than not detection or detection limit of $S$. mutans and $S$. sobrinus as score 0 for infants. ${ }^{49}$ The score for the mMSB-kit has been classified according to this report. Therefore, the score is able to be used to predict the value of $S$. mutans and $S$. sobrinus and therefore the caries risk. The mMSBkit also shows a positive correlation ( $r s=0.84$ ) for recollected saliva sample. Consequently, mMSBkit has been re-creation faithfully of modified MSB agar medium as these results show. Moreover, the sensitivity of detecting MS is higher by modified MSB agar medium when compared with conventional MSB agar medium, and an mMSB-kit is able to be used simply and at the chair side.)

\section{CONCLUSIONS}

We conclude that application of mMSB-kits and scores for the classifications they report are useful in that they allow accurate evaluation of MS and caries risk in clinical use.

\section{REFERENCES}

1. Keyes PH. Recent advances in dental caries research. Int Dent $J$ 1962;12:443-464.

2. Marsh $P$. The role of chemostats in the evaluation of antimicrobial agents for use in dental products. Microbiol Ecol Dis 1993;6:147-149.

3. Hamada S, Slade HD. Biology, immunology, and cariogenicity of Streptococcus mutans. Microbiol Rev 1973;44: 331 384

4. Loesche WJ. Role of the Streptococcus mutans, in human dental decay. Microbiol Rev 1986;50:353-380.

5. Hanada N. Current understanding of the cause of dental caries. Jpn J Infect Dis 2000;53:1-5.

6. Hamada S, Koga T and Ooshima T. Virulence factors of Streptococcus mutans, and dental caries prevention. J Dent Res 1984;63:407-411.

7. Bender GR, Sutton SVW and Marquis RE. Acid tolerance proton permeabilities, and membrane ATPases of oral streptococci. Infect Immun 1986;53:331-338.

8. Krasse B, Jordan HV, Edwardsson S, Svenson I, Trell L. The occurrence of certain "caries-inducing" streptococci 
in human dental plaque material-with special reference to frequency and activity of caries. Arch Oral Biol 1968;13: 911-918.

9. Hardie JM, Thomason PL, South RJ, et al. A longitudinal epidemiological study on dental plaque and the development of dental caries: interim results after two years. $J$ Dent Res 1977;56:90-98.

10. Jordan HV, Englander HR, Engler WO, Kulczyk S. Observations on the implantation and transmission of Streptococcus mutans in humans. J Dent Res 1972;51:515-518.

11. Gold OG, Jordan HV, van Houte J. A selective medium for Streptococcus mutans. Arch Oral Biol 1973;18:1357-1364.

12. Loesche WJ, Staffon LH. Longitudinal investigation of the role of Streptococcus mutans in human fissure decay. Infect Immun 1979;26:498-507.

13. Russell JI, MacFarlene TW, Aitchison TC, Stephen KW, Burchell CK. Caries prevalence and microbiological and salivary caries activity tests in Scottish adolescents. Community Dent Oral Epidemiol 1990;18:120-125.

14. de Soet JJ, van Dalen PJ, Applemelk BJ, de Graaff J. Identification of Streptococcus sobrinus with monoclonal antibodies. J Clin Microbiol 1987;25:2285-2288.

15. de Soet JJ, van Dalen PJ, Pavicic MJ, de Graaff J. Enumeration of mutans streptococci in clinical samples by using monoclonal antibodies. J Clin Microbiol 1990;28: 24672472.

16. Kneist S, Heinrich WR, Laurish L. Evaluation of a new caries risk test. Independent Dentistry 1999;76-84.

17. Li YH, Lau PC, Lee JH, Ellen RP, Cvitkovitch DG. Natural genetic transformation of Streptococcus mutans growing in biofilms. $J$ Bacteriol 2001;183:897-908.

18. Lorenz MG and Wackernagel W. Bacterial gene transfer by natural genetic transformation in the environment. Microbiol Rev 1994;58:563-602

19. Ida H, Hanada N, Sato T, Yoshikawa E. Clinical Biology of the mutans streptococci. Quintessence book (Tokyo) 2003; 82-89.

20. Oho T, Yamashita Y, Shimazaki Y, Kushiyama M, Koga T. Simple and rapid detection of Streptococcus mutans and Streptococcus sobrinus in human saliva by polymerase chain reaction. Oral Microbiol Immunol 2000;15:258-262.

21. Shiroza T, Ueda S, Kuramitsu HK. Sequence analysis of the gtfB gene from Streptococcus mutans. J Bacteriol 1987; 169:4263-4270.

22. Alaluusa S, Kleemola-Kujala E, Gronroos L, Evalahti M. Salivary caries-related tests as predictors of future caries increment in teenagers. A three-year longitudinal study. Oral Microbiol Immunol 1990;5:77-81.

23. Russell Jl, MacFarlane TW, Aitchison TC, Stephen KE, Burchell CK. Prediction of caries increment in Scottish adolescents. Community Dent Oral Epidemiol 1991;19:74-77.

24. Sullivan A, Schroder U. Systematic analysis of gingival state and salivary variables as predictors of caries from 5 to 7 years of age. Scand J Dent Res 1989;97:25-32.

25. Wilson RF, Ashley FP. Identification of caries risk in schoolchildren: salivary buffering capacity and bacterial counts, sugar intake and caries experience as predictors of 2-year and 3-year caries increment. Br Dent J 1989;167:99-102.

26. Buischi YAP, Axelsson P, Barbosa MF, Mayer M, Carmen $M$, de Oliviera L. Salivary $S$. mutans and caries prevalence in Brazilian schoolchildren. Community Dent Oral Epidemiol 1989;17:20-30.

27. Emilson CG, Krasse B. Support for and implications of the specific plaque hypothesis. Scand J Dent Res 1985;93:96104.

28. Kohler B, Andreen I, Jonsson B. The earlier the colonization by mutans streptococci, the higher the caries prevalence at 4 years of age. Oral Microbiol Immunol 1988;3:14-17.

29. Roeters FJ, van der Hoeven JS, Burgersdijk RC, Schaeken MJ. Lactobacilli, mutans streptococci and dental caries: a longitudinal study in 2-year-old children up to the age of 5 years. Caries Res 1995;29:272-279.

30. Berkowitz RJ. Causes, treatment and prevention of early childhood caries: a microbiologic perspective. J Can Dent Assoc 2003;69:304-307.

31. Jordan HV. Cultural methods for the identification and quantitation of Streptococcus mutans and lactobacilli in oral samples. Oral Microbiol Immunol 1986;1:23-27.

32. de Soet JJ, van Loveren C, Lammens AJ, et al. Differences in cariogenicity between fresh isolates of Streptococcus sobrinus and Streptococcus mutans. Caries Res 1991;25: 116-122.

33. Babaahmady KG, Challacombe SJ, Marsh PD, Newman HN. Ecological study of Streptococcus mutans, Streptococcus sobrinus and Lactobacillus spp. at sub-sites from approximal dental plaque from children. Caries Res 1998;32:5158.

34. Hirose H, Hirose K, Isogai E, Miura H, Ueda I. Close association between Streptococcus sobrinus in the saliva of young children and smooth-surface caries increment. Caries Res 1993;27:292-297.

35. Okada T, Tomita Y, Namiki Y, et al. Species constitution of mutans streptococci isolated from caries susceptible and caries free students. J Dent Res 1995;74 (special Issue): 501.

36. Erickson PR, McClintock KL, Green N, LaFleur J. Estimation of the caries-related risk associated with infant formulas. Pediatr Dent 1998;20:395-403.

37. Ramos-Gomez FJ, Weintraub JA, Gansky SA, Hoover $\mathrm{Cl}$, Featherstone J D. Bacterial, behavioral and environmental factors associated with early childhood caries. J Clin Pediatr Dent 2002;26:165-173.

38. Linke HA. New method for the isolation of Streptococcus mutans and its differentiation from other oral streptococci. J Clin Microbiol 1977;5:604-609.

39. Hirasawa M, Kiyono $H$, Shiota $T$, et al. Virulence of Streptococcus mutans: restoration of pathogenesis of a glucosyltransferase-defective mutant (C4). Infect Immun 1980; 27:915-921.

40. Takada K, Wyszomirska J, Shiota T. Serological characterization of Streptococcus mutans serotype polysaccharide $\mathrm{g}$ and its different molecular weight forms. Infect Immun 1984;45:464-469.

41. Schaeken MJ, van der Hoeven JS, Franken HC. Comparative recovery of Streptococcus mutans on five isolation media, including a new simple selective medium. $J$ Dent Res 1986;65:906-908.

42. Igarashi T, Yamamoto A, Goto N. Direct detection of Streptococcus mutans in human dental plaque by polymerase chain reaction. Oral Microbiol Immunol 1996;11:294-298.

43. Shiroza T, Shinozaki N, Watanabe T, Ikemi T, Fukushima $\mathrm{K}$, Abiko Y. Rapid isolation of chromosomal DNA from oral streptococci and polymerase chain reaction-oriented restriction fragment-length polymorphism analysis for genetic heterogeneity. Oral Microbiol Immunol 1998;13:11-16.

44. Hirasawa M, Takada K. Susceptibility of Streptococcus mutans and Streptococcus sobrinus to Cell Wall Inhibitors and Development of a Novel Selective Medium for $S$. sobrinus. Caries Res 2002;36:155-160.

45. Jensen B and Bratthall D. A new method for the Estimation of Mutans Streptococci in Human Saliva. J Dent Res 1989; 68:468-471.

46. Wade WG, Aldred MJ, Walker DM. An improved medium for isolation of Streptococcus mutans. J Med Microbiol 1986; 22:319-323.

47. Klock B, Krasse B. A comparison between different methods for prediction of caries activity. Scand J Dent Res 1979; 87:129-139.

48. Zickert I, Emilson CG., Krasse B. The effect of caries preventive measures in children highly infected with the bacterium Streptococcus mutans. Arch Oral Biol 1982;27:861868.

49. Kaneko N, Miyazaki H. Clinical Biology of the mutans streptococci. Quintessence book (Tokyo) 2003;90-97. 